\title{
Is research suffering at academic health centers?
}

Three new publications suggest that managed care's increased dominance is constricting the ability of America's 125 medical schools and teaching hospitalscollectively known as academic health centers (AHCs) - to carry out biomedical research. Although the publications provide no direct evidence that the quality or quantity of basic and clinical research is suffering, they claim that AHCs should be concerned about their future standing within the research community. And one of them asks National Institutes of Health $(\mathrm{NIH})$ to make up the monetary shortfall before AHC research is irretrievably affected.

Managed care, which now covers more than half of Americans with insurance, has made its mark by squeezing out inefficiency. But the insurers have achieved this by lowering physician and hospital payments while insisting that doctors see rising numbers of patients. The result is a 'double whammy' on AHCs, which traditionally care for a higher proportion of non-paying patients and are heavily involved in patient care and research.

According to a report released by the New York-based, nonprofit Commonwealth Fund, cross-subsidies for research are decreasing in markets with high managed care enrolment. Based on the knowledge that, at $\$ 42$ billion per

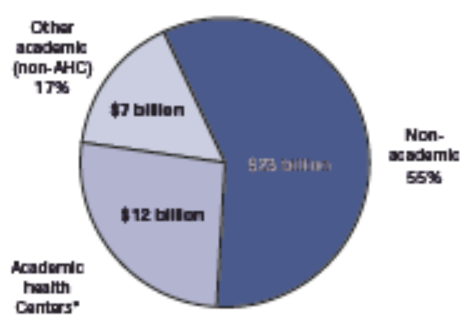

AHC contribution to national research effort for capital improvements through the NIH Blomedical Research Support Grant, which expired over a decade ago. It also recommends that the NIH pays more of the costs of research as grants often fall far short of what is needed to complete proposed work. In addition, the NIH should raise the $\$ 125,000$ celling on salaries for top-level investigators and should also increase support for training clinical researchers by "creating more numerous, longer, and more generous institutional training grants," instead of backing individual clinicians, suggests the document. $\mathrm{NIH}$ director of extramural research, Wendy Baldwin, could not be reached for comment.

A separate paper charges that AHCs located in areas where managed care predominates are getting less grant money from NIH and also have less institutional support to fall back on than those in areas served by traditional insurers (JAMA 281, 1093; 1999). Patient revenues typically help subsidize research, but the study found that in areas with the largest managed care groups, only 2.5 percent of research funds came from the institution, compared with 6.1 percent in markets with less penetration. And a recent survey of medical professionals found that 63.1 percent of faculty year, the federal government is the main provider of AHC research funds, the report makes several recommendations to avert catastrophe. For example, it suggests restoring funds members, directors of residency training. and department chairs, and 96.2 percent of deans, thought managed care had decreased faculty members' time for re-

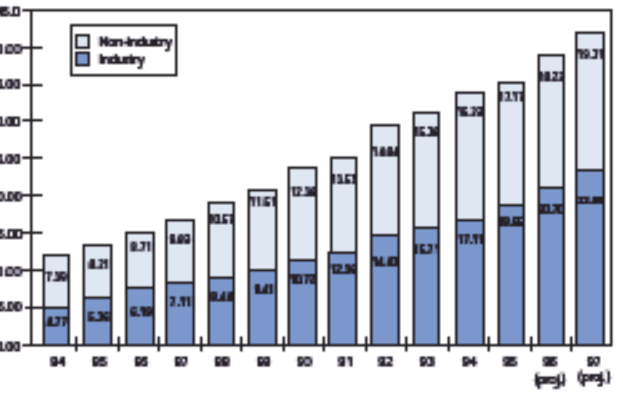

Health-related R\&D expenditure
Author of the paper, Joel Weissman says his is a wake-up call. "I don't want to be in the position of saying the sky is falling, because it's not," Weissman tells Nature Medicine. "But we're concerned about a gradual degradation of the kind of research that's been done over the last 20 years." He says the decline maybe hard to prove. "You're not going to find a smoking gun."

Massachusetts, like California, is dominated by managed care. According to Barry Eisenstein, vice president for Science \& Technology at the AHC, Beth Israel/Deaconess Hospital in Boston, the decline in clinical revenues has helped put the hospital in the red. This will hit cross-subsidies such as the 10 percent of the facility's $\$ 100$ million research budget that comes from internal funds. With losses projected this year and next, the hospital is hoping researchers can work within the same infrastructure while bringing in more grants. "I think we can get away with that for a while," says Eisenstein, who admits that there has not been any decline in $\mathrm{NIH}$ support, but says he expects it. "This institution is just starting to feel the enormous pinch of the managed care intrusion," he says.

Alicia Ault, Washington D.C.

\section{Italy promises to increase focus on rare diseases}

Under a specific commitment delineated in Italy's Health Plan for 1998-2000, the Italian Minister of Health is likely to announce the first national strategic research program on rare diseases this month. The initiative will replace the country's twenty or so disparate projects on rare diseases financed last year with a single research program. Research priorities and centers of excellence will be determined based on the analysis of a national registry of rare diseases, which was started at the end of March. The initiative is intended to tie in with a broader European program on rare diseases that is due to receive approval by the European parliament in the coming weeks.

A rare disease is defined as a one with a prevalence of 1 case per 2,000 people. There are around 5,000 rare diseases affecting approximately 20 million Europeans. Examples include retinoblastoma, neurofibromatosis, Wilms tumor, porphyria, amyotrophic lateral sclerosis and Whipple disease. The new program means that funding for research into these diseases should increase substantially from the IL 10.5 billion (US\$ 7 million) allotted to this field last year, according to Donato Greco, from the government's Higher Institute of Public Health.

The effort will add to, and draw on, the coordinated exchange of data and surveillance systems from the European database of rare diseases, which will be established under the European program with a five-year budget of Euro 6.5 million (US\$ 6 million) according to Luca Martinelli, program officer at the 